\title{
Adult feeding increases fecundity in female Helicoverpa armigera (Lepidoptera: Noctuidae)
}

\author{
Zeng-Ming SONG ${ }^{1,2}$, Zhe LI $^{1,2}$, DiAn-Mo LI ${ }^{1 *}$, BAO-Yu XIE $^{1}$ and JiNG-YuAN XIA ${ }^{3}$ \\ ${ }^{1}$ State Key Laboratory of Integrated Management of Pest Insects and Rodents, Institute of Zoology, Chinese Academy of Sciences, \\ Beijing, China \\ ${ }^{2}$ Graduate University of the Chinese Academy of Sciences, Beijing, China \\ ${ }^{3}$ National Agro-Tech Extension and Service Centre, Beijing, China
}

Key words. Noctuidae, Helicoverpa armigera, adult feeding, fecundity, lifespan

\begin{abstract}
The availability and quality of nectar for adults are thought to affect fecundity of the cotton bollworm, Helicoverpa armigera (Hübner) (Lepidoptera: Noctuidae). Experiments were conducted to analyze the effect of adult feeding on the fecundity, and oviposition pattern of moths, and larval performance (egg hatch). The moths were fed either on distilled water, honey solution, or one of a range of concentrations of sucrose solution. The results showed that diets with sugars significantly increased fecundity and adult lifespan. Lifespan, total numbers of eggs and egg mass were significantly higher for females that fed on sugar during adult life. Egg hatch (a measure of offspring fitness) decreased over time regardless of sucrose concentration, but had always higher levels in the groups fed sugars. The peak of the ovipositing period was delayed and prolonged, with more eggs deposited, when moths were fed on sugar solution. In conclusion, adult feeding increases the fecundity of female moths and plays an important role in enhancing the fitness of individual cotton bollworm offspring.
\end{abstract}

\section{INTRODUCTION}

Adult feeding plays an important role in determining the fecundity of most insects, also Lepidoptera (Boggs, 1986; Henry \& Thomas, 1999). Most adult Lepidoptera feed extensively on floral nectar. Some feed on a variety of other liquids, such as on fruit juice, excrement, animal secretions, and even blood. A few do not feed at all, especially in the females (Kevan \& Bakers, 1984) and rely on nutrients accumulated during the larval life.

The cotton bollworm, $H$. armigera (Hübner) is a widespread polyphagous pest of many agricultural and horticultural crops (Zalucki et al., 1986; Fitt, 1989) and can complete 3-4 generations each year in north China (Sheng et al., 1993; Li et al., 2005). Cotton (Gossypium hirsutum L.), corn (Zea mays L.) and peanut (Arachis hypogaea L.) are important host plants for the second to fourth generations of cotton bollworm in the field in northern China (Meng et al., 1962; Dong, 2002). Adult emergence in the field coincides with the flowering of the foraging plant. Cotton is the main nectar resource for the cotton bollworm providing food for the 3rd and 4th generations due to its long flowering period and wide distribution.

Adults of cotton bollworm ingest nectar and dew in the field, and in the laboratory will feed on a $10 \%$ honey or a sucrose solution (Wu et al., 1985; Li et al., 2005). The oocytes in female moths are not mature at adult emergence (Zalucki et al., 1986) and adult feeding is necessary for ovary and egg maturity. Wu et al. (1985) report that the cotton bollworm moth can maintain normal metabolic level for three days after emergence and then there is a decrease in metabolic rate beginning on day 4 if not fed nutrient supplements, at only half the level in the later stages of life.

Although adult feeding significantly affects lepidopteran reproduction (Topper, 1987; Willers et al., 1987; Wu \& Guo, 1996; Fischer et al., 2004) few studies consider the effect of adult feeding on fecundity and the pattern of ovipositon.

In this study, a range of sugar solutions were fed to adult cotton bollworms, simulating the nectar of the host plants in fields. The effects of adult feeding on fecundity and four related traits (lifespan, number of eggs, egg mass and egg hatching rate) were studied and the following questions addressed. Does adult feeding increase a moths' fecundity, and if so, do higher concentrations of sugar result in a higher fecundity? Answers to these questions help us to reveal cotton bollworm reproductive strategies and individual fitness, which highlight their population dynamics on different host plants.

\section{MATERIAL AND METHODS}

\section{Insect rearing and experimental conditions}

A laboratory population of $H$. armigera was established by collecting full-grown larvae from a cotton field in Raoyang County (38.24 N, 115.74 E), Hebei Province, China. Before testing, larvae were fed on a wheat-germ artificial diet (Wu \& Gong, 1997) for eight generations at $27^{\circ} \mathrm{C}$, a photoperiod of $14 \mathrm{~L}$ : $10 \mathrm{D}$ and relative humidity of $60 \pm 3 \%$. Mature larvae were allowed to pupate in a moist soil with a water content of $\pm 7 \%$ (soil was previously heated to $120^{\circ} \mathrm{C}$ for $2 \mathrm{~h}$ and sifted through a

\footnotetext{
* Corresponding author; e-mail: lidm@ioz.ac.cn
} 


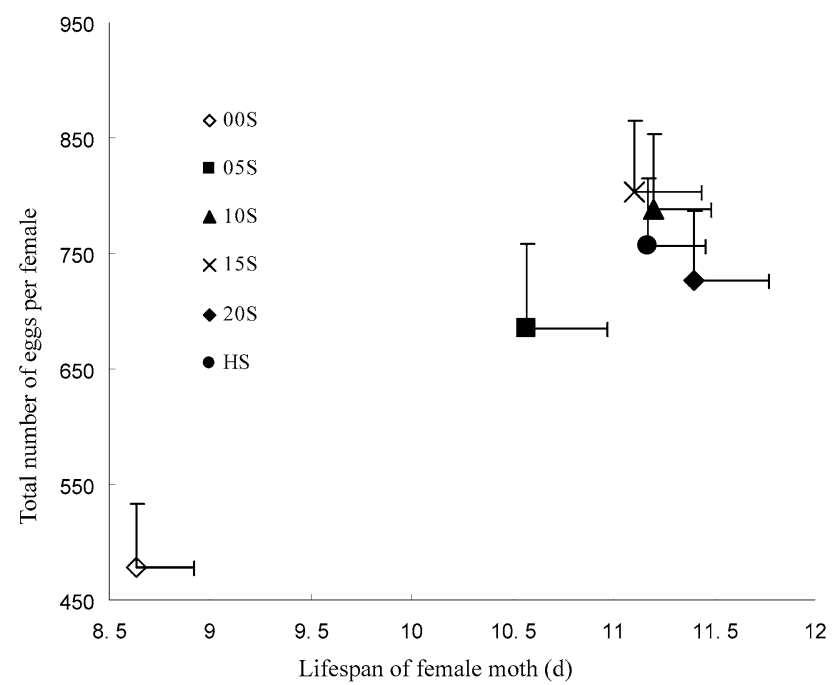

Fig. 1. Total number of eggs and lifespan of female moths of H. armigera.

sieve with 36 holes per $\mathrm{cm}^{2}$ ). Every day, $4 \mathrm{~h}$ into the scotophase, moths in the emergence cages were moved to empty cages according to sex and emergence date, fed with a $10 \%$ sucrose solution and used for stock rearing. Day of emergence was recorded as day 0 (Li et al., 2005).

\section{Influence of adult feeding on number of eggs laid}

Thirty female and thirty male pupae were randomly collected, divided into 6 groups and placed in separate $15 \mathrm{~cm}$ petri dishes. Groups were each provided with distilled water (00S), 10\% honey solution (HS), or a $5,10,15$ or $20 \%$ sucrose solution (05S, 10S, $15 \mathrm{~S}$ and $20 \mathrm{~S}$, respectively). After emergence, they were allowed to mate in cubic cages of $50 \mathrm{~cm}^{3}$. Mated male and female moths were transferred to cubic egg-laying containers of $25 \mathrm{~cm}^{3}$ with nylon gauze for oviposition ( $\mathrm{Li}$ et al., 2005). Solutions and nylon gauze were changed at the onset of the scotophase every day. Eggs were collected and counted until the moths died. The onset of oviposition was set as day 0 . The lifespan, days of oviposition and the number of eggs laid daily were also recorded.

\section{Influence of adult feeding on egg mass}

To test the effect of adult feeding on egg mass, eggs were collected on days 1, 4 and 7 after the onset of ovipositon. These eggs were weighed using an electronic balance $(0.1 \mathrm{mg}$ accuracy, Type AE 200, Mettler, Switzerland).

\section{Influence of adult feeding on egg hatch}

Eggs from the same batch were uniformly distributed in a 10 $\mathrm{cm}$ petri dish with moist filter paper in the bottom of the dish, and then kept at $27^{\circ} \mathrm{C}$, a photoperiod of $14 \mathrm{~L}: 10 \mathrm{D}$ and a relative humidity of $60 \pm 3 \%$. The number of newly hatched larvae was recorded and counted every $2 \mathrm{~h}$ on a single day.

\section{Statistical analysis}

Statistical analyses were performed using SPSS 13.0 (2004, SPSS Inc., Chicago, IL, USA). Two-factor $3 \times 6$ (day-by-diet) repeated measures ANOVAs were used to analyze the differences between groups. The Bonferroni $t$ test was used post hoc to determine main effect differences between the adult feeding regimes and day after the onset of oviposition, and to assess differences between groups over time. Regression analysis was conducted to test the relationship between percentage egg hatch and egg mass. Pearson correlation was used for number of eggs,

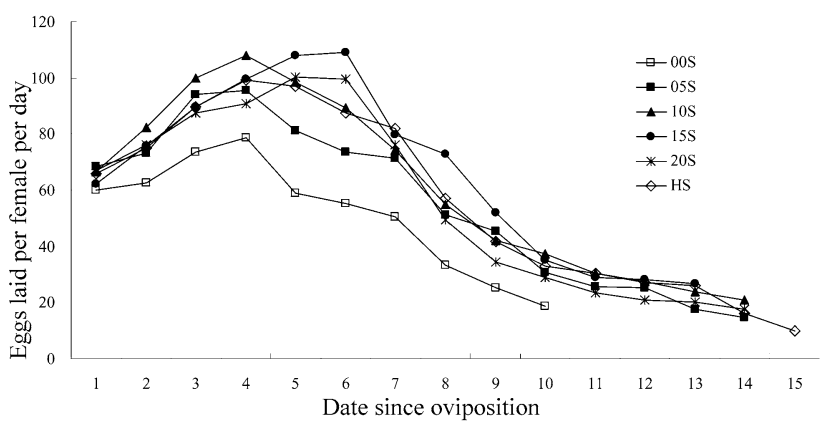

Fig. 2. Oviposition over time of females fed on different diets of $H$. armigera.

egg mass and egg hatch. Figures were generated using Excel (Microsoft Office Excel, 2003).

\section{RESULTS}

\section{Influence of adult feeding on number of eggs laid}

The mean lifespan of female moths in the 00S group was 8.6 days and they laid a total mean number of 488 eggs, while the values for the adult feeding groups were 11 days $\left(F_{(5,179)}=8.798, P<0.001\right)$ and 700 eggs $\left(F_{(5,179)}\right.$ $=3.650, P=0.004)$. Regression analysis showed that the total number of eggs was significantly affected by both feeding regimes and adult lifespan $\left(R=0.239, F_{(2,179)}=\right.$ 5.349, $P=0.006$ ) (Fig. 1).

In the 00S group, oviposition peaked on the 4rd day, 2 days before that of the adults fed on rich nutrient solutions (15S, 20S) (Fig. 2). A high level of oviposition was maintained for longer in the $10 \mathrm{~S}, 15 \mathrm{~S}$ and $20 \mathrm{~S}$ groups, although there was no difference in the total number of eggs laid among these groups.

\section{Influence of adult feeding on egg mass}

Two-way repeated measures ANOVA revealed a significant main effect of adult feeding regime $\left(F_{(5,442)}=\right.$ 4.91, $P<0.001)$ and day $\left(F_{(2,442)}=19.78, P<0.001\right)$, and no interaction $\left(F_{(10,442)}=1.61, P=0.10\right)$. The egg mass of the fed groups was higher than that of the 00S group, and in all groups decreased over time (Fig. 3). The Bonferroni $t$ test showed that the egg mass of the $05 \mathrm{~S}, 10 \mathrm{~S}$ and HS groups differed from that of the other groups $(P<0.01)$. The egg mass of these three groups showed a slight decrease from day 1 to 4 and a relatively large decrease from day 4 to 7 . The egg mass oviposited on day 7 was lighter than on days 1 and $4(P<0.01)$. The total number of eggs was positively correlated with egg mass on day 4 $(r=0.890, P=0.018)$ and there was no correlation between that on day $1(r=0.266, P=0.611)$ and day $7(r$ $=0.645, P=0.167)$.

\section{Influence of adult feeding on egg hatch}

Two-way repeated measures ANOVA of percentage hatch revealed a main effect of adult feeding regime $\left(F_{(5,253)}=2.73, P=0.02\right)$ and a significant main effect of day $\left(F_{(2,253)}=48.32, P<0.001\right)$, with no interaction $\left(F_{(10,253)}=1.28, P=0.24\right)$. Egg hatch on day 1 in the six groups was almost the same, and then decreased (Fig. 4). The Bonferroni $t$ test showed that egg hatch in the $10 \mathrm{~S}$, 


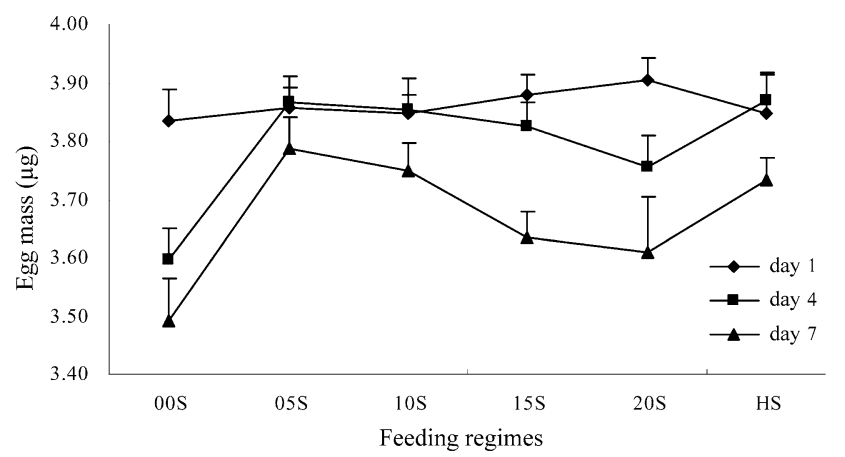

Fig. 3. Egg mass of female moths of $H$. armigera on day 1,4 and 7 after the onset of oviposition when fed different diets.

$15 \mathrm{~S}$ and $20 \mathrm{~S}$ groups was markedly higher than that in the other three groups $(P<0.01)$. It remained constant from day 1 to day 4 and decreased greatly from day 4 to day 7 . Significantly fewer of the eggs oviposited on day 7 hatched than of those oviposited on day 1 and day $4(P<$ $0.01)$. Total number of eggs was significantly positively correlated with egg hatch on day $7(r=0.956, P=0.003)$.

\section{DISCUSSION}

\section{Influence of adult feeding on the fecundity of cotton bollworm}

In this study, the results showed that four traits of cotton bollworm reproduction - total number of eggs, egg mass, egg hatch and female lifespan - increased when the adult moths were provided with nutrients. This reflects the importance of adult feeding, and is consistent with the results of Hou \& Sheng (2000), who report that females provided with supplementary food live longer and deposit more eggs.

The duration of the higher oviposition rate and lifespan of adults that were fed were both longer than those of the adults only given distilled water (Fig. 2). This shows that adult feeding prolongs life and enhances egg production. There was a significant main effect of adult feeding on egg mass and egg hatch $(P<0.01$, Figs 3 and 4). So, adult feeding enhances female fecundity in the cotton bollworm. Adult feeding is associated with a higher rate of egg laying before its eventual decline. Other reports note that adult feeding increases lepidopteran fecundity (Gunn \& Gatehouse, 1985; Carroll \& Quiring, 1992; Leahy \& Andow, 1994; Wu \& Guo, 1996; Mensah \& Gatehouse, 1998; Hou \& Sheng, 2000).

\section{Influence of food quality on fecundity in cotton bollworm}

Although adult feeding significantly enhanced female fecundity, the 5 feeding regimes resulted in no significant differences in total number of eggs, lifespan, egg mass and egg hatch. Egg mass and egg hatch clearly decreased in all feeding regimes from day 4 to day 7 , which suggests that adult feeding contributed more to fecundity in the early rather than the later stages. It is possible that larval nutrients ["capital reserves" (Sibly \& Calow, 1984, 1986)] account for the similarity in the fecundity of the 6 groups on day 1 , while the different adult feeding regimes

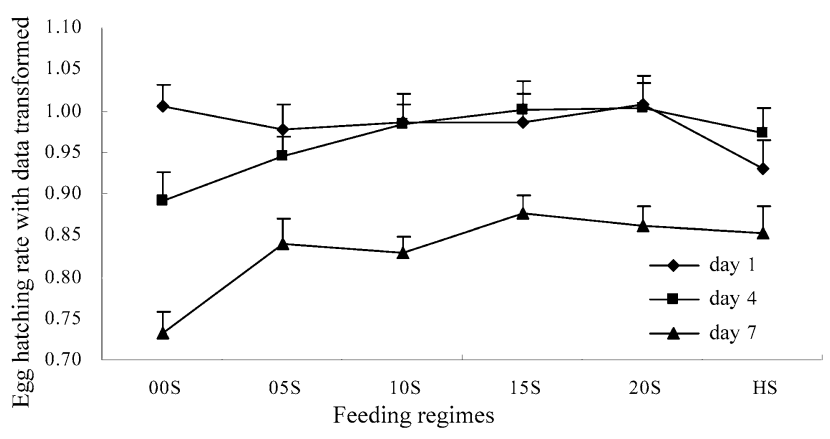

Fig. 4. Egg hatch of egg of female moths of $H$. armigera laid on day 1, 4 and 7 when adults were fed on different diets.

["income reserves" (Sibly \& Calow, 1984, 1986)] account for the differences between $00 \mathrm{~S}$ and the other feeding regimes on days 4 and 7 .

In terms of egg mass, that of the $20 \mathrm{~S}$ and $15 \mathrm{~S}$ group was significantly lower on days 4 and 7 than that of $05 \mathrm{~S}$, $10 \mathrm{~S}$ and HS $(P<0.01$, Fig. 3$)$, suggesting that the lower sugar concentration feeding regimes may contribute more water or carbohydrate in later life. Water and carbohydrates are essential for egg production in lepidoptera (Engelmann, 1970). In addition, egg hatch was higher when adults were fed higher concentrations of sugars (10S, 15S and 20S) rather than water 00S $(P<0.01)$, especially on day 7 , suggesting that high concentrations of sugar enhance egg hatch of late laid eggs.

The cotton bollworm is a widespread polyphagous pest of many agricultural and horticultural crops (Meng et al., 1962; Zalucki et al., 1986; Fitt, 1989). It has a wide host plant range including cotton, corn, peanut and soya bean among others. The moth transfers from one host to another over time and all hosts provide sufficient nectar.

\section{Influence of adult feeding on individual fitness}

Theories of life-history evolution describe age-specific growth, reproduction and survival, and in particular body size and the time schedule for attaining that size (Roff, 1992; Stearns, 1992). According to theory, there is a trade-off between immediately utilizing resources or storing them for future survival and reproduction. In our study, the moth appeared to invest resourses obtained during adult life in both survival and reproduction, as there was an increase not only in lifespan but also in total number of eggs, egg mass and egg hatch.

Egg mass and egg hatch reflect the fitness of individual offspring, and several studies demonstrate a positive correlation between egg mass and individual offspring fitness (Fischer \& Fiedler, 2001; Torres-Vila \& Rodríguez-Molina, 2002). There is a trade-off between egg mass and egg number in Lycaena hippothoe, with proportionally more of the heavier eggs hatching, which is considered as a timely response to environmental change (Fischer \& Fiedler, 2001). In our study, egg mass on day 4 was positively correlated with number of eggs, and there was a positive correlation between number of eggs and egg hatch on day 7. Therefore, adult feeding plays an important role in enhancing the fitness of individual cotton bollworm offspring. It was reported that egg 


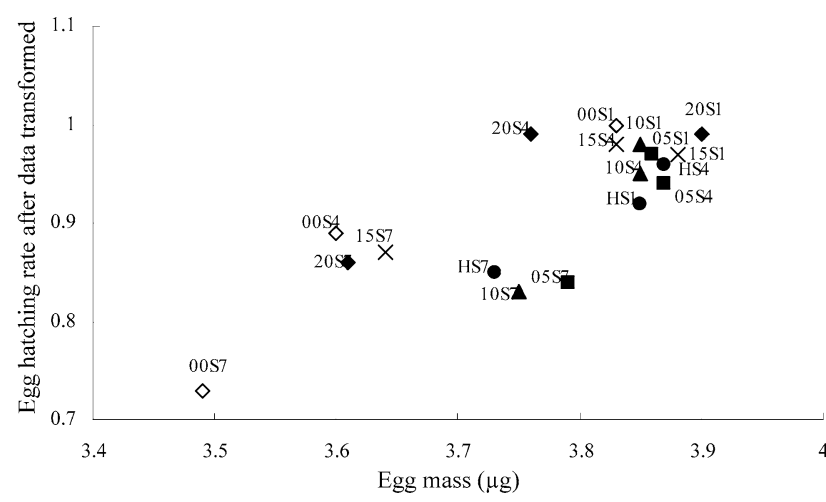

Fig. 5. Relationship between egg hatch and egg weight.

hatch and larval survival rate increases with egg mass (Boggs, 1997; Torres-Vila \& Rodríguez-Molina, 2002). However, in our study there was only a weak positive correlation between egg mass and egg hatch (Fig. 5).

ACKNOWLEDGEMENTS. We thank three anonymous referees for their valuable comments. For laboratory help, we thank K. Wu, P. Gong and Z. Liu. This work was supported by The Chinese National Key Basic Research Development Program, The National Nature Sciences Fund (No. 30571226).

\section{REFERENCES}

BogGs C.L. 1986: Reproductive strategies of female butterflies: variation in and constraints on fecundity. Ecol. Entomol. 70: $7-15$.

BogGS C.L. 1997: Reproductive allocation from reserves and income in butterfly species with different adult diets. Ecology 78: 181-191.

Carroll A.L. \& Quiring D.T. 1992: Sucrose ingestion by Zeiraphera canadensis Mut. and Free. (Lepidoptera: Tortricidae) increases longevity and lifetime fecundity but not oviposition rate. Can. Entomol. 124: 335-340.

Dong X. 2002: Classification of Chinese primary nectar plant. $J$. Bee 3: 31-32 [in Chinese, English abstr.].

Engelmann F. 1970: The Physiology of Insect Reproduction. Pergamon Press, New York, 307 pp.

Fischer K. \& FiEdLER K. 2001: Egg weight variation in the butterfly Lycaena hippothoe: more small or fewer large eggs? Popul. Ecol. 43: 105-109.

Fischer K., O'Brien D.M. \& Boggs C.L. 2004: Allocation of larval and adult resources to reproduction in a fruit-feeding butterfly. Funct. Ecol. 18: 656-663.

FITT G.P. 1989: The ecology of Heliothis species in relation to agro-ecosystems. Annu. Rev. Entomol. 34: 17-52.

Gunn A. \& Gatehouse A.G. 1985: Effects of the availability of food and water on reproduction in the African armyworm, Spodoptera exempta. Physiol. Entomol. 10: 53-63.

HeNRY Y.F. \& ThOMAs C.B. 1999: Reproductive performance and longevity of female European corn borer, Ostrinia nubilalis: effects of multiple mating, delay in mating, and adult feeding. J. Insect Physiol. 45: 385-392.
Hou M. \& Sheng C. 2000: Effects of adult feeding on reproduction of the cotton bollworm female moth. Acta Ecol. Sin. 20: 601-605 [in Chinese, English abstr.].

Kevan P.G. \& BaKer H.G. 1984: Insects on flowers. In Huffaker C.B. \& Raab R.L. (eds): Ecological Entomology. J. Wiley, New York, pp. 607-631.

LEAHY T.C. \& ANDOW D.A. 1994: Egg weight, fecundity, and longevity are increased by adult feeding in Ostrinia nubilalis (Lepidoptera: Pyralidae). Ann. Entomol. Soc. Am. 87: 342-349.

Li Z., Li D., XIE B., Ji R. \& Cui J. 2005: Effect of body size and larval experience on mate preference in Helicoverpa armigera (Hübner) (Lep., Noctuidae). J. Appl. Entomol. 129: 574-579.

Meng H., Zhang G. \& Ren S. 1962: A further studies on the cotton bollworm, Helicoverpa armigera (Hübner). Acta Entomol. Sin. 11: 72-82 [in Chinese, English abstr.].

Mensah B.A. \& Gatehouse A.G. 1998: Effect of larval phase and adult diet on fecundity and related traits in Spodoptera exempta. Entomol. Exp. Appl. 86: 331-336.

RofF D.A. 1992: The Evolution of Life Histories: Theory and Analysis. Chapman and Hall, New York, xii +535 pp.

Sheng C.F., Dong L. \& Su J.W. 1993: An approach to the cause of the outbreak of cotton bollworm in North China. J. Nat. Disasters 2(2): 20-26 [in Chinese, English abstr.].

SiBLY R.M. \& CALOW P. 1984: Direct and absorption costing in the evolution of life cycles. J. Theor. Biol. 111: 463-473.

Sibly R.M. \& Calow P. 1986: Physiological Ecology of Animals. Blackwell Scientific Publications, Oxford, 179 pp.

Stearns S.C. 1992: The Evolution of Life Histories. Oxford University Press, Oxford, $248 \mathrm{pp}$.

TOPPER C.P. 1987: Nocturnal behavior of adult of Heliothis armigera (Hübner) (Lepidoptera: Noctuidae) in the Sudan Gezira and pest control implications. Bull. Entomol. Res. 77: 541-554.

Torres-Vila L.M. \& Rodríguez-Molina M.C. 2002: Egg size variation and its relationship with larval performance in the Lepidoptera: the case of the European grapevine moth Lobesia botrana. Oikos 99: 272-283.

Willers J.L., Schneider J.C. \& Ramaswamy S.B. 1987: Fecundity, longevity and caloric patterns in female Heliothis virescens: changes with age due to flight and supplemental carbohydrate. J. Insect Physiol. 33: 803-808.

Wu K.J. \& Gong P.Y. 1997: A new and practical artificial diet for the cotton bollworm. Entomol. Sin. 4: 227-282.

Wu K.J., Gong P.Y. \& Li X.Z. 1985: Respiratory metabolism of the adults of the cotton bollworm, Heliothis armigera, and its energy expenditure. Acta Ecol. Sin. 5: 147-156 [in Chinese, English abstr.].

Wu K.M. \& Guo Y.Y. 1996: Effect of food quality on reproduction in Helicoverpa armigera (Hübner) (Lep., Noctuidae). Entomol. Knowl. 33: 203-205 [in Chinese, English abstr.].

Zalucki M.P., Daglish G., Firempong S. \& Twine P. 1986: The biology and ecology of Heliothis armigera (Hübner) and $\mathrm{H}$. punctigera Wallengren (Lepidoptera: Noctuidae) in Australia: what do we know? Aust. J. Zool. 34: 779-814.

Received November 7, 2006; revised and accepted May 22, 2007 